\title{
Achievement for All: Improving psychosocial outcomes for students with special educational needs and disabilities
}

\author{
Neil Humphrey*, Ann Lendrum, Alexandra Barlow, Michael Wigelsworth, Garry Squires
}

Educational Support and Inclusion, School of Education, University of Manchester, Oxford Road, Manchester, M13 9PL, United Kingdom

\section{A R T I C L E I N F O}

\section{Article history:}

Received 30 October 2012

Received in revised form 17 December 2012

Accepted 18 December 2012

Available online 1 February 2013

\section{Keywords:}

Special educational needs

Intervention

Evaluation

Bullying

Behaviour

Relationships

\begin{abstract}
A B S T R A C T
Students with special educational needs and disabilities (SEND) are at a greatly increased risk of experiencing poor psychosocial outcomes. Developing effective interventions that address the cause of these outcomes has therefore become a major policy priority in recent years. We report on a national evaluation of the Achievement for All (AfA) programme that was designed to improve outcomes for students with SEND through: (1) academic assessment, tracking and intervention, (2) structured conversations with parents, and (3) developing provision to improve wider outcomes (e.g. positive relationships). Using a quasi-experimental, pre-test-post-test control group design, we assessed the impact of AfA on teacher ratings of the behaviour problems, positive relationships and bullying of students with SEND over an 18-month period. Participants were 4758 students with SEND drawn from 323 schools across England. Our main impact analysis demonstrated that AfA had a significant impact on all three response variables when compared to usual practice. Hierarchical linear modelling of data from the intervention group highlighted a range of school-level contextual factors and implementation activities and student-level individual differences that moderated the impact of AfA on our study outcomes. The implications of our findings are discussed, and study strengths and limitations are noted.
\end{abstract}

Crown Copyright @ 2013 Published by Elsevier Ltd. All rights reserved.

\section{Introduction}

\subsection{Students with special educational needs and disabilities}

Students with special educational needs and disabilities (SEND) are widely considered to be the most vulnerable group of learners. Research consistently demonstrates that they are at risk of experiencing significantly worse academic and psychosocial outcomes through the course of schooling (e.g., Department for Education, 2010a; Van Cleave \& Davis, 2006; Zhang, Katsiyannis, \& Kortering, 2007). Such outcomes are of concern in themselves, but also have implications for later life opportunities (e.g., further study, employment) (Robinson \& Oppenheim, 1998).

International estimates of the prevalence of SEND vary - for example, 21\% in England (Department for Education, 2010a; Office for Standards in Education, 2010), 13.2\% in the USA (Institute of Education Sciences, 2011), and 7.6\% in Australia (Australian Institute of Health \& Welfare, 2004). This variation is accounted for by differences in definitions of what constitutes SEND and the social, political and legal influences that affect schooling systems from country to country (Robson, 2005). Whatever the estimate in a given nation, those with SEND always represent a significant proportion of the schoolaged population, and as such the development of effective models of intervention designed to ameliorate the effects noted

\footnotetext{
* Corresponding author. Tel.: +44 (0) 161253404.

E-mail address: neil.humphrey@manchester.ac.uk (N. Humphrey).
} 
above have become a policy priority in education systems across the world (Humphrey, Wigelsworth, Barlow, \& Squires, 2012).

The education of students with SEND has long been the subject of considerable controversy. This has focused primarily on the issue of inclusion/inclusive education (Thomas \& Loxley, 2007) and the field has seen massive debate in the last two decades that has encapsulated issues such as how SEND are defined and understood (Florian, 2007; Squires, 2012), whether the pedagogic needs of those with SEND are distinct from other learners (Lewis \& Norwich, 2005), what the research base tells us vis-à-vis the effectiveness of approaches to remediating SEND (Davis et al., 2004), and the relative contributions of values and rights vs. evidence-based considerations in the determination of educational policy and practice (Norwich, 2005).

At the policy level, there has been a significant ideological shift towards the promotion of inclusion. Nearly 100 governments signed the Salamanca Statement (United Nations Educational, Scientific and Cultural Organisation, 1994), and many countries have seen major SEND-related policy reforms (e.g. the Individuals with Disabilities Education Act in the United States, and the Excellence for All Children Green Paper in England). There are, however, concerns that mainstream schools' capacity to cater effectively for the needs of students with SEND have not kept pace with developments at the policy level. In the UK, there has been no real change in the numbers of pupils in segregated provision (Farrell, 2012). Analysis of national statistics in England demonstrates a significant attainment gap between students with and without SEND in core curriculum subjects beginning in early primary education and remaining stable throughout the different phases of schooling (Department for Education, 2010a). Similar longitudinal trends have been reported in the United States (McKinney \& Feagans, 1984) and elsewhere.

Research evidence also points to poor outcomes in psychosocial domains that are indicative of an impoverished social experience in school. For example, students with SEND are over-represented as victims (and in some cases, as perpetrators) of bullying (Monchy, Pijl, \& Zandberg, 2004; Sabornie, 1994; Thompson, Whitney, \& Smith, 1994; Van Cleave \& Davis, 2006). Furthermore, they typically experience poorer social relationships than children and young people with no identified difficulties. Hence, students with SEND report lower peer acceptance and have fewer friends and friendship groups compared to their peers (Frostad \& Pijl, 2007; Pijl, Frostad, \& Flem, 2008; ValÅs, 1999). Finally, learners identified as having SEND are at an increased risk of developing behavioural/conduct problems (Green, McGinnity, Meltzer, Ford, \& Goodman, 2005; McKinney \& Feagans, 1984). These outcomes are, of course, deeply inter-related (Frederickson \& Furnham, 2004; Kaukiainen et al., 2002; Monchy et al., 2004). So, for example, social support from peers is inversely related to exposure to bullying (Humphrey \& Symes, 2010). Similarly, behavioural difficulties can undermine the academic progress among those with SEND (Humphrey \& Squires, 2011a, 2011b), in addition to presenting a barrier to peer acceptance (Mand, 2007). Finally, research has established that the role of parents and their relationships with schools can mediate such outcomes (see Barlow \& Humphrey, 2012).

The aetiological factors underpinning the above outcomes are likely to be complex, multi-faceted and vary as a function of a range of individual and school differences. For instance, poorer social relationships may be attributable to difficulties in social skills (e.g. empathy, co-operation) experienced by some students (Frostad \& Pijl, 2007; Pijl et al., 2008), the stigmatisation associated with being labelled as having SEND (ValÅs, 1999), reduced peer acceptance of difference (Mand, 2007), and/or a variety of school processes and practices that may inadvertently hinder the quality and frequency of peer interaction, such as the way in which teaching assistants are deployed (Symes \& Humphrey, 2012).

\subsection{Integrated models of school-based intervention for students with SEND: the prevention perspective}

The last several decades have seen the development and evaluation of a large number of interventions designed to address the difficulties experienced by students with SEND. Literature reviews (e.g. Davis et al., 2004) and meta-analyses (e.g. Kavale, 2007) have demonstrated the impact of certain strategies and have helped to organise and shape the field. However, they also serve to highlight the fact that many interventions are extremely narrowly focused, typically being targeted at a single group, risk factor and/or outcome domain. Schools often implement such approaches in a fragmented manner that is not cost-efficient and can be difficult to sustain. This is known as the 'program for every problem' phenomenon (Domitrovich, Bradshaw, \& et al., 2010). What has been lacking to date is a school improvement framework that addresses both academic and non-academic outcomes for students with a variety of SEND in a way that enables them to synthesize the myriad interventions operating at different levels of the school (e.g. from systemic and organisational developments to specific, targeted strategies for students with particular needs).

The theoretical framework of school-based prevention may be a useful tool in this regard. In particular, the 'integrated prevention model' outlined by Domitrovich, Bradshaw, and et al. (2010) offers great promise. This model reflects the complexities of the aetiological factors underpinning outcomes for students with SEND outlined above, positing that a range of individual and environmental factors can place children at risk of negative outcomes, and furthermore that these outcomes are inter-related. Domitrovich, Bradshaw, et al. (2010) propose that approaches to intervention that focus narrowly on a single risk factor or outcome domain are less likely to be successful than those that target multiple factors. Furthermore, they argue that effective school-based prevention should combine universal, school-wide approaches with targeted/indicated intervention for specific groups of students. Finally, the authors suggest that an integrated model, in which independent strategies or programmes are fused into one coherent framework for intervention in a co-ordinated manner will result in a synergistic effect. The rationale for such a model is provided in terms of (a) comprehensiveness, (b) maximised intervention exposure, (c) the additive or multiplicative effects caused by the interaction of different strategies, (d) reduced 'initiative overload' and improved sustainability, and (e) improved potential for high quality implementation. 


\subsubsection{Mediators of intervention impact at school and student levels}

The effectiveness of any such intervention or instructional regime always varies as a function of the quality of its enactment. As such, a significant body of research has begun to explore the determinants of implementation quality (Durlak, 2010; Durlak \& DuPre, 2008). The quality of the implementation of an intervention is related to fidelity, the extent to which a programme is implemented as intended by its developers (Dusenbury, Brannigan, Hansen, Walsh, \& Falco, 2005). Interventions are rarely implemented with complete fidelity and this has consistently been found to impact on the achievement of expected outcomes (Elliott \& Mihalic, 2004; Raudenbush, 2008; Rogers, 2003). Local adaptations to programmes are considered to be inevitable (Ringwalt \& Ennett, 2003) and although some - such as surface-level alterations to resources - may be beneficial, deeper or structural modifications are likely to reduce programme effectiveness (Blakely et al., 1987). These may include, for example, the omission of critical elements of the programme, or reduced 'dosage' (that is, delivery of the prescribed number and length of sessions). Adaptations may be intentional as implementers seek to enhance the goodness-of-fit between an intervention and their own setting, or unintentional, due perhaps to a lack of understanding of how an intervention is intended to achieve change. Adaptations may also be made in response to barriers to implementation (Lendrum, 2010).

Barriers to and facilitators of the implementation of school-based interventions may be present at multiple levels (Durlak \& DuPre, 2008; Greenberg, Domitrovich, Graczyk, Zins, \& Services, 2005). Programme characteristics, such as complexity (Rogers, 2003), quality of resources (Greenberg et al., 2005) or clarity about delivery models (Humphrey, Lendrum, \& Wigelsworth, 2010) may all affect implementation. At the classroom level, teachers' 'will and skill' may also have an impact on how the intervention is delivered (ibid). Individual teaching styles, conflicting priorities, attitudes to change and beliefs about the value of an intervention are likely to influence willingness to implement it, whilst knowledge and understanding of what is required to effect change and the skills and self-efficacy to achieve this are required (Durlak \& DuPre, 2008; Greenberg et al., 2005; Humphrey et al., 2010). Classroom climate, relationships, and the responsiveness of students to an intervention are also relevant (Dane \& Schneider, 1998).

At a broader level, factors within the implementation environment such as the capacity for change, compatibility of a new intervention with existing school practices and ethos, and the perception of the benefits or need for a specific intervention may also impact on implementation (Durlak \& DuPre, 2008). The support of the head-teacher for an intervention is also influential (Kam, Greenberg, \& Walls, 2003). Such support should be active, however, and may include allocating limited curriculum time or resources, providing initial and on-going training opportunities and support for implementers, and sanctioning release time from the classroom to attend these (Humphrey et al., 2010; Lendrum, 2010). Research suggests that some of these factors may be more significant than others. For example, leadership (Gottfredson \& Gottfredson, 2002) and staff 'will and skill' (Humphrey et al., 2010) are considered vital. Nonetheless, it is the complex interaction of multiple factors across and within levels rather than any single, dominant factor that determines effective implementation (Durlak \& DuPre, 2008; Lendrum, 2010).

In addition to the above, the theoretical constructs underpinning work on school-based prevention (e.g. risk, protection and resilience) suggest that intervention outcomes are also likely to vary as a function of individual differences between students rather than being distributed in a uniform fashion. Masten and Obradovic (2006) note that the resilience demonstrated by individuals that is imparted through intervention may vary as a function of context, time, stressor, and adaptive domain. However, few studies have explored this to date (Durlak, Weissberg, Dymnicki, Taylor, \& Schellinger, 2011). Those in which appropriate analyses have been conducted have found evidence in favour of a 'differential gains' (as opposed to 'universal gains') hypothesis. So, for example, the 'You Can Do It!' preventive intervention in Australia only improved the literacy scores of children who were poorer readers to begin with (Ashdown \& Bernard, 2011). In the same country, the evaluation of the Kidsmatter initiative demonstrated positive effects only for children who began the study with clinically significant mental health difficulties (Slee et al., 2009). Finally, analysis of the benefits of the Second Step curriculum in Norway revealed much greater improvement in outcomes for students from low socio-economic backgrounds than for their more affluent peers (Holsen, Iversen, \& Smith, 2009).

\subsection{The Achievement for All (AfA) programme}

The Achievement for All (AfA) programme was piloted from 2009 to 2011 in England. It was supported by a £31 million grant from the Department for Education, enabling delivery in over 450 schools during this period. AfA was conceptualised as a means to support schools to provide better opportunities for learners with SEND to fulfil their potential. There were three main strands in the pilot version. Strand 1,'Assessment, tracking and intervention' (ATI), included the use of the Assessing Pupil Progress (APP) approach to track students' progress, the setting of curriculum targets and implementation of appropriate interventions to support children and young people with SEND to make progress in their learning (Department for Children Schools \& Families, 2009). Strand 2, 'Structured conversations with parents' (SCP), focused on the use of a clear framework for developing an open, on-going dialogue with parents about their child's learning and life in school. Training was provided for schools, which emphasized the building of parental engagement and confidence via a four-stage model (explore, focus, plan, review) in up to three structured conversations per year. Finally, Strand 3, 'Provision for developing wider outcomes' (PWO), involved schools developing/enhancing school-wide strategies and key actions to support children and young people with SEND to make progress in their attendance, improve behaviour, reduce exposure to bullying, develop positive relationships and increase wider participation in school life (e.g. after-school clubs). Participating schools were 
given strategic support in their implementation of these strands by professionals working at local (AfA leads and advisory teachers) and regional (National Strategies coordinators) levels.

The AfA pilot programme aligns closely with the principles of Domitrovich, Bradshaw, and et al.'s (2010) integrated prevention model. First, it reflects the need to address multiple risk factors and outcomes for students with SEND. Second, it presents a synergy between school-wide strategies and targeted provision. Third, it provides a framework for fusing independent strategies and programmes in a co-ordinated manner. The design of AfA also reflects aspects of the schoolbased prevention evidence base that are known to promote high quality implementation and ultimately, sustainability. So, for example, the programme provides a balance between prescriptiveness (e.g. structured conversations with parents) and flexibility (e.g. provision for developing wider outcomes) that can secure consistent delivery but also be responsive to local context and need (Castro, Barrera, \& Martinez, 2004). AfA also involved training for school staff in key aspects of programme delivery (e.g. structured conversations with parents) in addition to on-going 'support and challenge' visits from the aforementioned external professionals, akin to technical support and assistance. Both training and technical assistance have been associated with improved implementation in the prevention literature (Durlak \& DuPre, 2008; Greenberg et al., 2005; Joyce \& Showers, 2002).

\subsection{The current study: rationale and hypotheses}

In 2009 the authors were commissioned by the Department for Education to conduct a national evaluation of the AfA programme pilot. The aims of our evaluation were (a) to determine the impact of AfA on a variety of outcomes for learners with SEND, and (b) to identify the processes and practices that were most effective in improving these outcomes. The main study focused on the following outcomes: (i) achievement in English and Maths, (ii) parental engagement and confidence, and (iii) wider outcomes (e.g. behaviour, bullying, positive relationships) (Humphrey \& Squires, 2010, 2011a, 2011b). In this article we focus on the impact of AfA on the latter set of outcomes, and the various school- and individual-level factors that moderated this impact. Interested readers who wish to know more about the impact of AfA on other outcomes modelled in our study are referred to the final project report (Humphrey \& Squires, 2011b) and associated academic outputs (e.g. Barlow et al., forthcoming; Lendrum et al., forthcoming).

The study was seen as crucial in determining whether the AfA pilot should be brought to scale nationally. However, it also provided an opportunity for a significant contribution to the extant evaluation literature on interventions for students with SEND. Furthermore, from a methodological/analytic perspective, there was an opportunity to advance the field beyond basic considerations of the average effect of a given intervention, because this can mask potentially important variability arising from differences between both individuals and the schools in which the intervention takes place. This was deemed to be particularly important given the flexible nature of elements of the AfA programme and its pilot status (see above).

The theory and logic of the integrated prevention model (see Section 1.2 above) suggests that programmes like AfA should be an effective means through which to improve outcomes for vulnerable students. In light of this, we predicted that AfA would have a statistically significant impact on (a) behaviour problems, (b) positive relationships and (c) bullying of students with SEND when compared to usual practice (Hypothesis 1). However, research also suggests that intervention impact is mediated by a variety of factors at school and individual levels (see Section 1.2.1 above). In light of this, we predicted that both school- and individual-level differences would account for statistically significant proportions of the variance in each of the three response variables noted above among students in the intervention group (Hypothesis 2). Finally, we predicted that a range of school- and individual-level explanatory variables would help to explain significant proportions of the variance in each of the three response variables among students in the intervention group (Hypothesis 3 ).

\section{Method}

The current study comprised of two main components. The first component utilised a quasi-experimental, pre-test-posttest control group design ${ }^{1}$ to determine the impact of AfA when compared to usual practice (Hypothesis 1 ). The second component focused on the intervention group only, and utilised a longitudinal, multi-level, natural variation design to determine the amount of variation in our response variables that existed between and within schools (Hypothesis 2) and to identify the characteristics at school and individual levels that explained significant variation in these outcomes (Hypothesis 3). In both components of the study our response variables were (a) behaviour problems, (b) positive relationships, and (c) bullying among students with SEND.

\subsection{Sample}

Sampling was purposive and multi-stage in nature. For the AfA pilot programme, 10 Local Authorities (LAs - are 'school districts') were selected by the Department for Education to broadly represent the diversity inherent in LAs across the country (e.g. population density, socio-economic factors, geographical location). Schools were then chosen in each LA by

\footnotetext{
${ }^{1}$ Random allocation to the intervention and control arms of the trial was not possible because intervention schools had already been selected by the point at which the study was commissioned.
} 
Table 1

School sample characteristics and national averages.

\begin{tabular}{|c|c|c|c|c|c|}
\hline \multirow[t]{2}{*}{ School characteristic } & \multirow[t]{2}{*}{$\begin{array}{l}\text { AfA sample } \\
\text { mean }(S D)\end{array}$} & \multirow[t]{2}{*}{$\begin{array}{l}\text { Control sample } \\
\text { mean (SD) }\end{array}$} & \multirow[t]{2}{*}{$\begin{array}{l}\text { National } \\
\text { average }\end{array}$} & \multicolumn{2}{|c|}{$\begin{array}{l}\text { Magnitude of difference (expressed as } \\
\text { Cohen's } d \text { ) }\end{array}$} \\
\hline & & & & $\begin{array}{l}\text { National-AfA } \\
\text { sample }\end{array}$ & $\begin{array}{l}\text { National-control } \\
\text { sample }\end{array}$ \\
\hline $\begin{array}{l}\text { Proportion of students eligible for free } \\
\text { school meals (FSM) }\end{array}$ & $23.17(15.44)$ & $19.72(13.80)$ & $16.95^{\mathrm{a}}$ & 0.40 & 0.20 \\
\hline $\begin{array}{l}\text { Proportion of students speaking English } \\
\text { as an additional language (EAL) }\end{array}$ & $17.05(24.89)$ & $20.52(31.41)$ & $13.8^{\mathrm{a}}$ & 0.13 & 0.21 \\
\hline Proportion of students with SEND & $23.38(6.16)$ & $18.69(3.39)$ & $20.8^{\mathrm{a}}$ & 0.42 & 0.62 \\
\hline Attendance - overall absence (\% half days) & $6.48(4.45)$ & $6.13(1.11)$ & $6.05^{\mathrm{b}}$ & 0.10 & 0.07 \\
\hline $\begin{array}{l}\text { Proportion of students achieving expected } \\
\text { level of academic attainment }\end{array}$ & $59.14(14.53)$ & $64.88(18.30)$ & $63.2^{\mathrm{c}, \mathrm{d}}$ & 0.28 & 0.01 \\
\hline
\end{tabular}

a Department for Education (2010b).

b Department for Education (2010c).

c Department for Education (2010d).

d Department for Education (2010e).

senior staff on the basis of them representing the diversity of schools inherent within the area (e.g. attainment, ethnicity). Within each school, students with SEND in Years 1 and 5 (primary schools - aged 5/6 and 9/10 respectively) and 7 and 10 (secondary schools - aged $11 / 12$ and $14 / 15$ respectively) were selected to participate (see below).

The research team recruited schools to form the usual practice/control group from within the 10 participating LAs. Control group schools were selected on the basis of willingness to participate and their similarity to AfA/intervention schools on a range of salient characteristics (e.g. attendance, attainment).

\subsubsection{Schools}

The intervention group comprised $308^{2}$ schools and the control group comprised 15 schools. Given the non-random nature of the sampling/recruitment procedures for the AfA pilot programme, it was important to establish that these schools broadly represented the broader population of schools in England in terms of key characteristics. In this vein, Table 1 presents a comparison of our school sample and all state-funded mainstream schools in England by attendance, attainment, free school meal eligibility (FSM), proportion of students speaking English as an additional language (EAL), and proportion of students with SEND (SEND).

Using the standard effect size cut-offs established by Cohen (1992), inspection of Table 1 reveals that in all but one case (proportion of students with SEND in the control group) the differences in school characteristics between our two study groups and national averages were marginal ( $<0.2$ in four cases) or small ( $0.2-0.49$ in five cases). This increases confidence in the representativeness of our school sample and therefore the external validity of the evaluation.

\subsubsection{Students}

4758 students with SEND (4562 intervention group; 196 control group) participated in the study. As above, the nonrandom nature of the sample made it important to establish that these students broadly represented the broader population of learners with SEND in England in terms of their key characteristics. In this vein, Table 2 presents a comparison of our student sample and all students with SEND in England by sex, FSM, EAL, SEND provision, and SEND primary need.

Inspection of Table 2 reveals only marginal differences between our two study groups and national averages in terms of socio-demographic characteristics (e.g., gender, FSM, EAL). This pattern is largely replicated for the two SEND variables (provision and primary need), but there are some exceptions. First, there are notable differences between the control group students and national averages in terms of SEND provision. Second, both study groups contained larger proportions of students with moderate learning difficulties (MLD) than is typical nationally. Finally, there were lower proportions of students with behavioural, emotional and social difficulties (BESD) in the control group than the average across England. These differences most likely reflect natural variation in the application of the identification and assessment guidance that governs SEND provision in English schools (Department for Education \& Skills, 2001; Squires, Humphrey, Barlow, \& Wigelsworth, 2012). Thus, as with the school characteristics noted above, the student sample composition can be said to be largely representative of the population from which it was drawn.

\subsection{Measures}

Our response variables were measured using the Wider Outcomes Survey for Teachers (WOST) (Humphrey \& Squires, 2011a, 2011b). The WOST provides indices of students' behaviour, bullying and positive relationships, and was designed specifically for the assessment of students with SEND. It consists of series of statements (e.g., "[student name] is called names

\footnotetext{
${ }^{2}$ This figure is lower than the overall number of participating schools as data were missing for a small number, and since our focus was on students with SEND in mainstream schools, data from special schools and pupil referral units were excluded from the analysis.
} 
Table 2

Student sample characteristics and national averages.

\begin{tabular}{|c|c|c|c|c|c|c|}
\hline \multirow[t]{2}{*}{ Student characteristic } & & \multirow[t]{2}{*}{ AfA sample $\%(N)$} & \multirow{2}{*}{$\begin{array}{l}\text { Control } \\
\text { sample \% }(N)\end{array}$} & \multirow{2}{*}{$\begin{array}{l}\text { National } \\
\text { average }^{\mathrm{a}}\end{array}$} & \multicolumn{2}{|l|}{ \% Difference } \\
\hline & & & & & $\begin{array}{l}\text { National-AfA } \\
\text { sample }\end{array}$ & $\begin{array}{l}\text { National-control } \\
\text { sample }\end{array}$ \\
\hline Sex - proportion of male students & & $61.6 \%(2951)$ & $65.3 \%(128)$ & $63.5 \%$ & -1.9 & 1.8 \\
\hline $\begin{array}{l}\text { Proportion eligible for free school } \\
\text { meals (FSM) }\end{array}$ & & $32.7 \%(1569)$ & $25 \%(49)$ & $28.0 \%$ & 4.7 & -3.0 \\
\hline $\begin{array}{l}\text { Proportion speaking English as } \\
\text { an additional language (EAL) }\end{array}$ & & $16.3 \%(782)$ & $14.8 \%(29)$ & $14.8 \%$ & 1.5 & 0 \\
\hline \multirow{4}{*}{$\begin{array}{l}\text { SEND provision - proportion of } \\
\text { students at each stage of provision }\end{array}$} & SA & $55.4 \%(2652)$ & $37.2 \%(73)$ & $60.0 \%$ & -4.6 & -22.8 \\
\hline & SAP & $31.65 \%(1515)$ & $40.3 \%(79)$ & $32.0 \%$ & -0.4 & 8.3 \\
\hline & SSEN & $10 \%(478)$ & $21.9 \%(43)$ & $8.0 \%$ & 2.0 & 13.9 \\
\hline & Unclassified & $2 \%(95)$ & 0 & - & - & - \\
\hline \multirow{13}{*}{$\begin{array}{l}\text { SEND primary need - proportion } \\
\text { in each category of need }\end{array}$} & SpLD & $14.6 \%(700)$ & $11.7 \%(23)$ & $13.3 \%$ & 1.3 & -1.6 \\
\hline & MLD & 38.35 (1837) & $40.1 \%(77)$ & $24.7 \%$ & 13.6 & 15.4 \\
\hline & SLD & $2.3 \%(111)$ & $3.6 \%(7)$ & $1.2 \%$ & 1.1 & 2.4 \\
\hline & PMLD & $0.6 \%(30)$ & $2 \%(4)$ & $0.3 \%$ & 0.3 & 1.7 \\
\hline & BESD & $17.6 \%(843)$ & $7.7 \%(15)$ & $24.4 \%$ & -6.8 & -16.7 \\
\hline & SLCN & $11.3 \%(540)$ & $13.8 \%(27)$ & $17.2 \%$ & -5.9 & -3.4 \\
\hline & ASD & $3.9 \%(189)$ & $7.1 \%(14)$ & $6.6 \%$ & -2.7 & 0.5 \\
\hline & VI & $0.6 \%(30)$ & 0 & $1.3 \%$ & -0.7 & -1.3 \\
\hline & $\mathrm{HI}$ & $1.5 \%(70)$ & $5.6 \%(11)$ & $2.3 \%$ & -0.8 & 3.3 \\
\hline & MSI & $0.1 \%(7)$ & 0 & $0.2 \%$ & -0.1 & -0.2 \\
\hline & PD & $2.5 \%(120)$ & $5.1 \%(10)$ & $3.7 \%$ & -1.2 & 1.4 \\
\hline & Other & $4.2 \%(202)$ & $1.5 \%(3)$ & $5.1 \%$ & -0.9 & -3.6 \\
\hline & Unclassified & $1.6 \%(76)$ & $2.5 \%(5)$ & - & - & - \\
\hline
\end{tabular}

${ }^{\mathrm{a}}$ Department for Education (2010a).

or teased by other children") to which the respondent indicates a level of agreement on a four-point rating scale (e.g. never, rarely, sometimes, often). The WOST consists of 20 items, with 7 each for bullying and positive relationships, and 6 covering behaviour difficulties. Psychometric analyses conducted during the development and refinement of the WOST indicate that it meets several of the key criteria set out by Terwee et al. (2007). Specifically, it has good content validity (exemplified by the clear measurement aims, target population, concepts, item selection and reduction, and item interpretability reported by its developers), strong internal consistency (established through acceptable fit indicators in confirmatory factor analysis and Cronbach's Alpha co-efficients of $>0.9$ for each domain), excellent construct validity (demonstrated by analyses showing that scores are consistent with a range of theoretically derived hypotheses concerning the concepts under scrutiny) acceptable floor ( $>15 \%$ evident in the behaviour and bullying domains) and no ceiling effects (less than $15 \%$ for all domains), and good interpretability (aided by normative scores) (Humphrey and Squires, 2011b). Item responses are averaged for each domain of the WOST such that overall scores always range from 0 to 3, with higher scores indicative of higher levels of the measurement domain in question.

'Background' socio-demographic and other descriptive data at school (e.g. attainment) and individual (e.g. gender) levels were collected by the authors from various sources including the national pupil database (for individual-level data), EDUBASE performance tables (www.edubase.gov.uk) and/or information provided by LAs (for school-level data). AfA implementation data was collected using a school-level survey completed by the programme co-ordinator in each participating school. Data was matched at individual and school levels using unique identification numbers that are used in student and school censuses in England.

Table 3 provides a breakdown of each of the variables noted above, including a basic description and associating scoring protocols.

\subsection{Procedure}

\subsubsection{Data collection}

Pre-test data for each of the three response variables was collected via online surveys in Jan/Feb 2010, with post-test data collected approximately 18 months later in June/July 2011. School-level AfA implementation data was collected via online surveys in April/May 2011.

\footnotetext{
${ }^{3}$ Students in England currently receive SEND provision characterised by the following procedures: at School Action (SA), a teacher has noticed that a given student is experiencing difficulty and makes adjustments to his/her practice accordingly. At School Action Plus (SAP), the procedures outlined for SA are supplemented by assessment and possible intervention by external agencies (e.g. educational psychology services). Finally, a student may undergo statutory assessment leading to a Statement of Special Educational Needs (SSEN), a legal document outlining the nature of his/her needs and how these needs should be supported. Provision at SSEN typically secures additional financial and/or human resources to support students in school.
} 
Table 3

Explanatory and response variables used in HLM analyses.

\begin{tabular}{llll}
\hline Level & & Variable & Scoring protocol \\
\hline LA & - & - & - \\
School & Contextual/implementation & Urbanicity & Urban (0) vs. rural (1)
\end{tabular}

environment variables

Size

\%EAL

\%FSM

$\%$ SAP/SSEN

$\%$ SA

\%Achievement

\%Absence

School behaviour problems School positive relationships School bullying

AfA implementation quality variables

Number of full-time equivalent students on roll (e.g. $1000=\mathrm{a}$ school with one thousand pupils)

Proportion of students at school speaking English as an additional language (EAL), expressed as a percentage from 0 to 100

Proportion of students at school eligible for free school meals (FSM), expressed as a percentage from 0 to 100

Proportion of students in school in receipt of SEND provision at School Action Plus (SAP) or with Statements of SEND (SSEN), expressed as a percentage from 0 to 100

As above but for SA

Proportion of students achieving at least National Curriculum Level 4 in English and Maths (primary) or at least $5 \mathrm{~A}^{*}$-C GCSE grades including English and Maths (secondary), expressed as a percentage from 0 to 100

Average proportion of pupil absence from school (expressed as $\%$, from 0 to 100 )

Aggregated pupil behaviour scores at pre-test (0-3)

Aggregated pupil positive relationships scores at pre-test $(0-3)$

Aggregated pupil bullying scores at pre-test $(0-3)$

"Is AfA school lead a member of the SLT?" No (0) vs. Yes (1)

APP moderation

APP sharing

APP target review teachers

APP target review parents Intervention planning

Intervention form

Information access

Parent communication

Parent relationships

Structured conversation dosage Structured conversation fidelity

Positive relationships strategies implementation

Behaviour problems strategies implementation

Bullying strategies implementation Attendance strategies implementation Wider participation strategies implementation

Gender

Year group

Ethnicity

Language

FSM eligibility

SEND provision ${ }^{3}$

"How are judgements surrounding assessment of pupil progress moderated?" Scale scored from 1 to 5 , with higher scores indicating increased use of moderation

"Are targets set using the progression guidance shared with parents?" No (0) vs. Yes (1)

"Are these targets reviewed by teachers on a termly basis?" Never/Rarely/Often/Always

As above but for parents

"Who is involved in planning interventions?" Scale scored from 1 to 5 , with higher scores indicating larger numbers of people

"What form do these interventions take?" Scale scored from 1 to 4 , with higher scores indicating more comprehensive forms of intervention

"Who has access to student information?" Scale from 1 to 6 , with higher scores indicating larger numbers of people "How do parents get to know how their children are doing?" Scale scored from 1 to 8 , with higher scores indicating more methods of communication

"How would you describe the school's relationship with parents prior to AfA?" Very Poor/Poor/Good/Excellent

$\%$ of students at school from whom at least two SCPs took place Extent to which schools reported following nine key principles of SCP practice. Scale scored from 0 to 36, with higher scores indicating greater fidelity to guidance

Extent to which school reported progress in implementation of strategies to facilitate positive relationships. Scale scored from 0 to 3 , with higher scores indicating greater implementation progress

As above but for behaviour problems

As above but for bullying

As above but for attendance

As above but for wider participation

Male/Female

Year $1 /$ Year $5 /$ Year $7 /$ Year10

White British, Asian, Black, Mixed, Chinese, other, unclassified English, other, unclassified

Not eligible (0) vs. eligible (1)

School Action (SA), School Action Plus (SAP), Statement of Special Educational Needs (SSEN), Unclassified 
Table 3 (Continued)

\begin{tabular}{|c|c|c|}
\hline Level & Variable & Scoring protocol \\
\hline & SEND primary need & $\begin{array}{l}\text { Specific Learning Difficulties (SpLD), Moderate learning } \\
\text { difficulties (MLD), Severe Learning Difficulties (SLD), Profound } \\
\text { and Multiple Learning Difficulties (PMLD), behavioural, emo- } \\
\text { tional and social difficulties (BESD), Speech, Language and } \\
\text { Communication Needs (SLCN), Autism Spectrum Disorder } \\
\text { (ASD), Visual Impairment (VI), Hearing Impairment (HI), } \\
\text { Multiple Sensory Impairment (MSI), Physical Disability (PD), } \\
\text { other, unclassified }\end{array}$ \\
\hline & Maths achievement & $\begin{array}{l}\text { Maths National Curriculum point score at pre-test, scored from } \\
1 \text { to } 65 \text {, with higher scores indicating greater achievement }\end{array}$ \\
\hline & English achievement & As above but for English \\
\hline & Attendance & $\begin{array}{l}\text { Proportion of days attending school at pre-test, expressed as a } \\
\text { percentage from } 0 \text { to } 100\end{array}$ \\
\hline & Response variable pre-test & $\begin{array}{l}\text { Mean response variable score (e.g. behaviour, positive relation- } \\
\text { ships, bullying) at pre-test, scored from } 0 \text { to } 3 \text {, with higher } \\
\text { scores indicating higher levels of the measurement domain in } \\
\text { question }\end{array}$ \\
\hline $\begin{array}{l}\text { Response variable } \\
\text { post-test }\end{array}$ & & $\begin{array}{l}\text { Mean response variable score (e.g. behaviour, positive relation- } \\
\text { ships, bullying) at post-test, scored from } 0 \text { to } 3 \text {, with higher } \\
\text { scores indicating higher levels of the measurement domain in } \\
\text { question }\end{array}$ \\
\hline
\end{tabular}

\subsubsection{Intervention}

Two staff (typically the headteacher and special educational needs co-ordinator) from each participating school attended initial 'launch conferences' that were held in each of the 10 LAs. These conferences served as a means to introduce the AfA pilot and provide some initial training around key principles of the programme. These were followed by more specific training for staff in specific aspects of programme delivery (e.g. structured conversation and APP training). Further training was then cascaded in each school to 'Key Teachers' of students in the study cohort. In primary schools this was the typically a given child's class teacher; in secondary schools, it was typically his/her form tutor.

Each school worked in collaboration with their LA AFA lead and advisory teachers to develop, implement and monitor an action plan for delivery of the programme. The generic delivery model for the intervention was as follows:

1. Strand 1 (ATI)

a. Use of APP and Progression Guidance to track students' progress

b. Setting of curriculum targets and implementation of appropriate interventions to support children and young people to work towards those targets. These interventions typically comprised a blend of 1:1 tuition, adjustment of curriculum planning and teaching strategies to address gaps in learning, and use of specialist resources or guided group work to construct inclusive learning sequences

c. Sharing of academic targets and data with parents, through structured conversation and other media (e.g. emails, text messages)

d. Assessment and tracking at class and school level, supported by meetings to share levels of progress within schools among teachers and management

e. Use of Information Management Systems (such as 'Assessment Manager') to support the above

2. Strand 2 (SCP)

a. A target of three structured conversations per school year involving the Key Teacher and parents/carers of every student with SEND in the study cohort. Where appropriate, students' views were also gathered

b. Each structured conversation scheduled for approximately 40-60 min

c. Drawing up of a contract or agreement with parents/carers about the purpose and outcomes of the conversations

d. Utilisation of a four-stage model in each conversation, as follows:

1. Explore - active listening, paraphrasing, communicating, understanding

2. Focus - identifying priorities, clarifying key issues

3. Plan - agreeing targets, seeking outcomes, developing a plan

4. Review - summarising, clarifying next steps, arranging further communication

e. The area(s) of focus in each SCP to be mutually determined by the Key Teacher and parents/carers, but always directly pertaining to the students' progress in school and any issues influencing this

3. Strand 3 (PWO)

a. Schools to introduce and/or build upon existing school-wide and, where appropriate, targeted interventions designed to support students to attend school more frequently, improve behaviour, reduce exposure to bullying, develop positive relationships and increase wider participation in school life (e.g. after-school clubs)

b. Attendance initiatives included (but were not limited to) reward systems, increased communication with parents (e.g. through the SCP), using a school attendance officer, and making the curriculum more relevant/accessible to students 
Table 4

Change in psychosocial outcomes during the intervention period.

\begin{tabular}{|c|c|c|c|c|c|c|}
\hline & & $N$ & Pre-test mean (SD) & Post-test mean (SD) & Pre-post change mean (SD) & Change upper/lower CI \\
\hline \multirow[t]{3}{*}{ AFA } & Behaviour problems & 4424 & $0.617(0.733)$ & $0.597(0.706)$ & $-0.020(0.655)$ & $-0.001 /-0.039$ \\
\hline & Positive relationships & 4560 & $2.060(0.569)$ & $2.155(0.562)$ & $0.094(0.585)$ & $0.111 / 0.075$ \\
\hline & Bullying & 4375 & $0.528(0.618)$ & $0.493(0.611)$ & $-0.036(0.682)$ & $-0.016 /-0.056$ \\
\hline \multirow[t]{3}{*}{ Control } & Behaviour problems & 194 & $0.440(0.640)$ & $0.593(0.721)$ & $0.153(0.626)$ & $0.242 / 0.065$ \\
\hline & Positive relationships & 193 & $2.074(0.578)$ & $2.071(0.575)$ & $-0.003(0.589)$ & $0.081 /-0.087$ \\
\hline & Bullying & 194 & $0.436(0.574)$ & $0.588(0.694)$ & $0.152(0.592)$ & $0.236 / 0.068$ \\
\hline
\end{tabular}

c. Behaviour initiatives included (but were not limited to) behavioural expectations systems, staff training, reward systems and individual/small group interventions

d. Bullying initiatives included (but were not limited to) peer-based techniques (e.g. mentoring), restorative justice approaches, and use of social and emotional learning materials

e. Positive relationships initiatives included (but were not limited to) use of Circle Time, peer-based approaches (e.g. buddy benches), and social and emotional learning activities.

f. Wider participation initiatives included (but were not limited to) provision of ICT facilities for students and their parents, private and voluntary sector projects, and developing extended services projects specifically for targeted pupils

\section{Results}

\subsection{Impact of AFA on psychosocial outcomes for students with SEND (Hypothesis 1)}

Table 4 provides the descriptive statistics for the (a) behaviour problems, (b) positive relationships and (c) bullying/ victimisation of students with SEND in the intervention and control groups at pre- and post-test. In view of the sample imbalance, accompanying 95\% confidence intervals are presented for the change in scores from pre- to post-test.

The data in Table 4 shows an increase in positive relationships among students in the intervention group during the course of the AfA pilot programme, compared to a decrease among students in the control group during the same period. Also evident are reductions in behaviour problems and bullying among intervention group students, compared to increases in these two domains for control group students. With the marginal exception of changes in positive relationships (AfA lower $\mathrm{CI}=0.075$, control upper $\mathrm{CI}=0.081)$, the $95 \%$ confidence intervals for the intervention and control groups do not overlap, increasing the likely generalizability of the findings in spite of the sample imbalance. Error bar charts (Fig. 1 below) illustrate these effects well.

The above trends were investigated in more detail using multivariate analysis of variance (MANOVA). The MANOVA identified a main effect of treatment group, $F(3,4373)=6.55, p<.001$. More specifically, there were statistically significant effects for positive relationships $\left[F(1,4375)=5.62, p<.05\right.$, partial $\left.\eta^{2}=.001\right]$, behaviour problems $[F(1,4375)=13.36$, $p<.001$, partial $\left.\eta^{2}=.003\right]$, and bullying $\left[F(1,4587)=4.74, p<.01\right.$, partial $\left.\eta^{2}=.003\right]$, in all cases in favour of the intervention group. In terms of effect size, the treatment effect for positive relationships was $d=0.17$ (Cohen, 1992), equivalent to a 7percentile-point gain for students attending AfA schools (using Cohen's $U^{3}$ index - Durlak, 2009). For bullying, $d=0.28$, equivalent to an 11-percentile-point reduction as a result of attending an AfA school. Finally, for behaviour problems, $d=0.26$, equivalent to a 10 -percentile-point reduction for students in AfA schools.

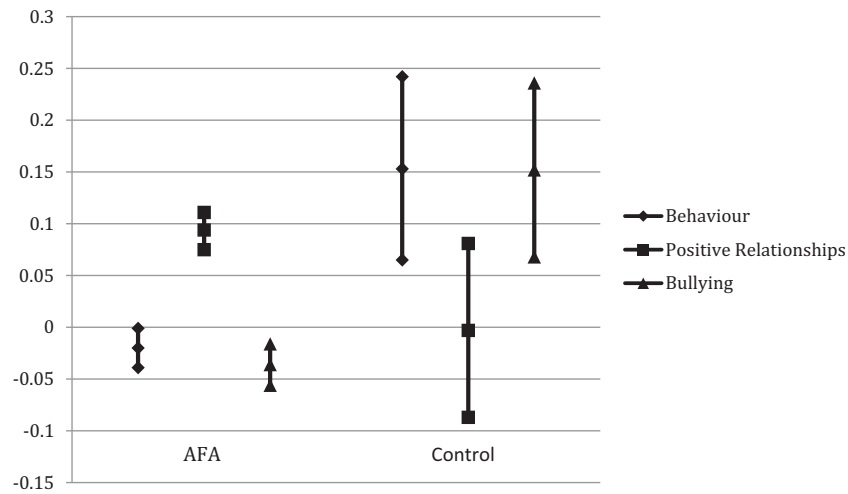

Fig. 1. Change in psychosocial outcomes during the intervention period (mean and confidence intervals). 
Table 5

School and pupil level variables associated with statistically significant changes in pupils' behaviour problems during the AfA pilot (primary schools).

\begin{tabular}{|c|c|c|c|c|c|c|c|}
\hline \multicolumn{4}{|c|}{$\beta_{0 i j k}=0.567(0.026)$} & \multicolumn{4}{|l|}{$\beta_{0 i j k}=0.983(0.489)$} \\
\hline & Co-efficient $\beta$ & SE & $p$ & & Co-efficient $\beta$ & SE & $p$ \\
\hline \multirow[t]{2}{*}{ LA level } & 0.001 & 0.003 & .374 & LA Level & 0.000 & 0.000 & - \\
\hline & $0.2 \%$ & & & & $0 \%$ & & \\
\hline \multirow[t]{7}{*}{ School level } & 0.055 & 0.010 & $<.001$ & School level & 0.024 & 0.006 & $<.001$ \\
\hline & $11.8 \%$ & & & & $9.8 \%$ & & \\
\hline & & & & \%Achievement & -0.006 & 0.002 & .002 \\
\hline & & & & Leadership (compared to 'no') & -0.132 & 0.070 & .031 \\
\hline & & & & Intervention form (total count $0-5$ ) & -0.074 & 0.031 & .009 \\
\hline & & & & Structured conversation dosage & +0.002 & 0.001 & .024 \\
\hline & & & & School behaviour problems & -0.153 & 0.079 & .028 \\
\hline \multirow[t]{8}{*}{ Pupil level } & 0.411 & 0.013 & $<.001$ & Pupil level & 0.222 & 0.008 & $<.001$ \\
\hline & $88 \%$ & & & & $90.2 \%$ & & \\
\hline & & & & Sex (compared to 'male') & -0.066 (if 'female') & 0.028 & .009 \\
\hline & & & & Year Group & +0.021 (if 'year 5’) & 0.013 & .053 \\
\hline & & & & SEND provision (compared to 'SA') & +0.112 (if 'SSEN') & 0.065 & .043 \\
\hline & & & & SEND primary need (compared to 'MLD') & +0.326 (if 'BESD') & 0.042 & $<.001$ \\
\hline & & & & & -0.200 (if 'PD') & 0.096 & .019 \\
\hline & & & & Behaviour problems pre-test & +0.486 & 0.021 & $<.001$ \\
\hline \multicolumn{4}{|c|}{$-2 *$ Log likelihood $=4735.110$} & $-2 *$ Log likelihood $=2109.366$ & & & \\
\hline \multicolumn{4}{|c|}{$X^{2}(65, n=1509)=2625.74, p<.001$} & & & & \\
\hline
\end{tabular}

In sum, our analyses provided support for Hypotheses 1a, 1b and 1c. Furthermore, bivariate correlation analyses of the magnitude of changes in behaviour problems and bullying $(r=0.510, p<.001)$, behaviour problems and positive relationships $(r=-0.351, p<.001)$, and positive relationships and bullying $(r=-0.297, p<.001)$ suggested inter-related processes at work, as noted in the preceding literature review.

\subsection{School- and individual-level differences in psychosocial outcomes among students in the intervention group (Hypotheses 2 and 3)}

A series of fixed-effects, 'intercept as outcomes' (Raudenbush \& Bryk, 2002) hierarchical linear models (HLM) were produced in order to determine the amount of variation in our response variables that existed between and within schools (Hypothesis 2) and to identify the characteristics at school and individual levels that explained significant variation in these outcomes (Hypothesis 3). These models are presented in Tables 5-10. In each case, the first stage of the analysis involved the

Table 6

School and pupil level variables associated with statistically significant changes in pupils' behaviour problems during the AfA pilot (secondary schools).

\begin{tabular}{|c|c|c|c|c|c|c|c|}
\hline \multicolumn{4}{|c|}{$\beta_{0 i j k}=0.690(0.050)$} & \multicolumn{4}{|l|}{$\beta_{0 i j k}=1.584(1.088)$} \\
\hline & Co-efficient $\beta$ & SE & $p$ & & Co-efficient $\beta$ & SE & $p$ \\
\hline \multirow[t]{2}{*}{ LA level } & 0.000 & 0.000 & - & LA Level & 0.000 & 0.000 & - \\
\hline & $0 \%$ & & & & $0 \%$ & & \\
\hline \multirow[t]{5}{*}{ School level } & 0.091 & 0.024 & $<.001$ & School level & 0.000 & 0.000 & - \\
\hline & $15.7 \%$ & & & & $0 \%$ & & \\
\hline & & & & APP moderation (total count $0-5$ ) & +0.166 & 0.058 & .052 \\
\hline & & & & $\begin{array}{l}\text { APP target review teachers } \\
\text { (compared to 'never') }\end{array}$ & -0.996 (if ‘often') & 0.464 & .082 \\
\hline & & & & $\begin{array}{l}\text { Parent relationships } \\
\text { (compared to 'very poor') }\end{array}$ & -0.653 (if 'poor') & 0.230 & .052 \\
\hline \multirow[t]{13}{*}{ Pupil level } & 0.487 & 0.017 & $<.001$ & Pupil level & 0.294 & 0.014 & $<.001$ \\
\hline & $84.3 \%$ & & & & $100 \%$ & & \\
\hline & & & & Year group (compared to 'Year 7') & -0.037 (if 'Year $10^{\prime}$ ) & 0.014 & .004 \\
\hline & & & & Sex (compared to 'male') & -0.125 (if 'female') & 0.042 & .001 \\
\hline & & & & FSM eligibility (compared to 'no') & +0.082 (if ‘yes') & 0.043 & .026 \\
\hline & & & & Language (compared to 'English') & -0.171 (if 'other') & 0.092 & .032 \\
\hline & & & & Maths achievement (1-65) & -0.007 & 0.003 & .010 \\
\hline & & & & English achievement (1-65) & -0.004 & 0.002 & .023 \\
\hline & & & & $\%$ attendance $(08 / 09)$ & -0.004 & 0.002 & .023 \\
\hline & & & & SEND provision (compared to 'SA') & -0.185 (if 'SSEN') & 0.072 & .005 \\
\hline & & & & SEND primary need (compared to 'MLD') & +0.167 (if 'BESD') & 0.055 & .001 \\
\hline & & & & & -0.279 (if 'ASD') & 0.128 & .015 \\
\hline & & & & Behaviour problems pre-test & +0.453 & 0.029 & $<.001$ \\
\hline \multicolumn{4}{|c|}{$-2 *$ Log likelihood = 3544.999} & $-2 *$ Log likelihood $=1455.295$ & & & \\
\hline \multicolumn{4}{|c|}{$X^{2}(68, n=902)=2089.70, p<.001$} & & & & \\
\hline
\end{tabular}


Table 7

School and pupil level variables associated with statistically significant changes in pupils' positive relationships during the AfA pilot (primary schools).

\begin{tabular}{|c|c|c|c|c|c|c|c|}
\hline \multicolumn{4}{|c|}{$\beta_{0 i j k}=2.222(0.020)$} & \multicolumn{4}{|l|}{$\beta_{0 i j k}=0.254(7.569)$} \\
\hline & Co-efficient $\beta$ & SE & $p$ & & Co-efficient $\beta$ & SE & $p$ \\
\hline \multirow[t]{2}{*}{ LA level } & 0.000 & 0.002 & - & LA level & 0.000 & 0.000 & - \\
\hline & $0 \%$ & & & & $0 \%$ & & \\
\hline \multirow[t]{13}{*}{ School level } & 0.044 & 0.007 & $<.001$ & School level & 0.012 & 0.004 & - \\
\hline & $14 \%$ & & & & $5.9 \%$ & & \\
\hline & & & & $\%$ SAP/SSEN & -0.012 & 0.003 & $<.001$ \\
\hline & & & & School positive relationships & -0.176 & 0.076 & .011 \\
\hline & & & & APP target review teachers & -0.520 (if 'often') & 0.281 & .034 \\
\hline & & & & (compared to 'never') & -0.568 (if 'always') & 0.278 & .022 \\
\hline & & & & APP target review parents & +0.431 (if 'rarely') & 0.144 & .002 \\
\hline & & & & (compared to 'never') & +0.497 (if 'often') & 0.130 & $<.001$ \\
\hline & & & & & +0.426 (if 'always') & 0.132 & $<.001$ \\
\hline & & & & APP sharing & -0.130 (if ‘yes) & 0.070 & .033 \\
\hline & & & & Parent communication $(0-8)$ & -0.041 & 0.019 & .017 \\
\hline & & & & Information access (total count $0-6$ ) & +0.024 & 0.017 & .081 \\
\hline & & & & Structured conversation dosage & +0.002 & 0001 & .024 \\
\hline \multirow[t]{10}{*}{ Pupil level } & 0.271 & 0.008 & $<.001$ & Pupil level & 0.192 & 0.007 & $<.001$ \\
\hline & $86 \%$ & & & & $94.1 \%$ & & \\
\hline & & & & Year group & -0.045 (if 'Year 5') & 0.012 & $<.001$ \\
\hline & & & & SEND provision (compared to 'SA') & -0.104 (if 'SSEN') & 0.060 & .042 \\
\hline & & & & & -0.465 (if ‘unknown') & 0.131 & $<.001$ \\
\hline & & & & SEND primary need & -0.196 (if ‘ASD’) & 0.064 & .001 \\
\hline & & & & (Compared to 'MLD') & -0.253 (if ‘BESD’) & 0.038 & $<.001$ \\
\hline & & & & & +0.147 (if ‘unknown’) & 0.052 & .002 \\
\hline & & & & English achievement (1-65) & +0.011 & 0.005 & .014 \\
\hline & & & & Positive relationships pre-test & +0.430 & 0.025 & $<.001$ \\
\hline \multicolumn{4}{|c|}{$-2 *$ Log likelihood $=3779.375$} & $-2 *$ Log likelihood $=1870.560$ & & & \\
\hline \multicolumn{8}{|c|}{$X^{2}(66, n=1516)=1908.82, p<.001$} \\
\hline
\end{tabular}

production of an unconditional model that enabled approximations of the variance in the response variable attributable to each level (Hypothesis 2). A conditional model was then executed, in which the various explanatory variables at the school and individual levels (see Table 3) were included. The fit to the data of the unconditional and conditional models was then assessed by computing and comparing their $2 * \log$ likelihood values at convergence. This allowed us to infer that the inclusion of the explanatory variables in the full model improved predictive power to a statistically significant degree (Hypothesis 3). In the interests of brevity, only those explanatory variables where $p<.10$ are reported in the tables.

Table 8

School and pupil level variables associated with statistically significant changes in pupils' positive relationships during the AfA pilot (secondary schools).

\begin{tabular}{|c|c|c|c|c|c|c|c|}
\hline \multicolumn{4}{|c|}{$\beta_{0 i j k}=2.222(0.020)$} & \multicolumn{4}{|l|}{$\beta_{0 i j k}=0.254(7.569)$} \\
\hline & Co-efficient $\beta$ & SE & $p$ & & Co-efficient $\beta$ & SE & $p$ \\
\hline \multirow[t]{2}{*}{ LA level } & 0.000 & 0.000 & - & LA level & 0.000 & 0.000 & - \\
\hline & $0 \%$ & & & & $0 \%$ & & \\
\hline \multirow[t]{8}{*}{ School level } & 0.034 & 0.009 & $<.001$ & School level & 0.000 & 0.000 & - \\
\hline & $11.4 \%$ & & & & $0 \%$ & & \\
\hline & & & & \%SAP/SSEN & +0.019 & 0.009 & .063 \\
\hline & & & & APP target review teachers & +1.334 (if 'often') & 0.334 & .014 \\
\hline & & & & (compared to 'never') & +1.204 (if 'always') & 0.350 & .021 \\
\hline & & & & $\begin{array}{l}\text { APP target review parents } \\
\text { (compared to 'never') }\end{array}$ & +0.230 (if ‘often') & 0.076 & .028 \\
\hline & & & & APP sharing (compared to 'no') & -0.458 (if 'yes') & 0.238 & .075 \\
\hline & & & & Structured conversation fidelity $(0-36)$ & +0.042 & 0.013 & .024 \\
\hline \multirow[t]{10}{*}{ Pupil level } & 0.265 & 0.009 & $<.001$ & Pupil level & 0.190 & 0.008 & $<.001$ \\
\hline & $88.6 \%$ & & & & $100 \%$ & & \\
\hline & & & & SEND primary need (compared to 'MLD') & -0.141 (if 'BESD’) & 0.041 & $<.001$ \\
\hline & & & & & +0.244 (if ‘HI’) & 0.097 & .006 \\
\hline & & & & & -0.203 (if 'PD’) & 0.085 & .009 \\
\hline & & & & SEND provision (compared to SA) & +0.202 (if 'unknown') & 0.095 & .017 \\
\hline & & & & Ethnicity (compared to 'White British') & -0.437 (if 'Chinese') & 0.233 & .030 \\
\hline & & & & FSM eligibility (compared to 'no') & -0.107 (if 'yes') & 0.033 & $<.001$ \\
\hline & & & & Maths achievement (1-65) & +0.009 & 0.003 & .001 \\
\hline & & & & Positive relationships pre-test & +0.364 & 0.028 & $<.001$ \\
\hline \multicolumn{4}{|c|}{$-2 *$ Log likelihood $=2661.550$} & $-2 *$ Log likelihood = 1192.336 & & & \\
\hline \multicolumn{8}{|c|}{$X^{2}(67, n=1012)=1469.21, p<.001$} \\
\hline
\end{tabular}


Table 9

School and pupil level variables associated with statistically significant changes in bullying of pupils during the AfA pilot (primary schools).

\begin{tabular}{|c|c|c|c|c|c|c|c|}
\hline \multicolumn{4}{|c|}{$\beta_{0 i j k}=2.476(0.023)$} & \multicolumn{4}{|l|}{$\beta_{0 i j k}=1.497(0.555)$} \\
\hline & Co-efficient $\beta$ & SE & $p$ & & Co-efficient $\beta$ & SE & $p$ \\
\hline \multirow[t]{2}{*}{ LA level } & 0.00 & 0.000 & - & LA level & 0.001 & 0.003 & .374 \\
\hline & $0 \%$ & & & & $0.4 \%$ & & \\
\hline \multirow[t]{7}{*}{ School level } & 0.072 & 0.010 & $<.001$ & School level & 0.045 & 0.009 & $<.001$ \\
\hline & $20.2 \%$ & & & & $17.9 \%$ & & \\
\hline & & & & $\% S A$ & -0.007 & 0.004 & .042 \\
\hline & & & & \%EAL & +0.003 & 0.001 & .017 \\
\hline & & & & APP target review parents & -0.575 (if ‘rarely’) & 0.217 & .005 \\
\hline & & & & (compared to 'never') & -0.422 (if ‘often’) & 0.194 & .016 \\
\hline & & & & & -0.364 (if ‘always') & 0.198 & .034 \\
\hline \multirow[t]{9}{*}{ Pupil level } & 0.285 & 0.009 & $<.001$ & Pupil level & 0.206 & 0.008 & $<.001$ \\
\hline & $79.8 \%$ & & & & $81.7 \%$ & & \\
\hline & & & & Year group & $+0.065($ if 'Year 5') & 0.013 & $<.001$ \\
\hline & & & & Language & -0.118 (if ‘Other’) & 0.059 & .023 \\
\hline & & & & \% Attendance (09/10) & -0.005 & 0.002 & .006 \\
\hline & & & & English achievement (1-65) & -0.013 & 0.006 & .015 \\
\hline & & & & SEND primary need & +0.213 (if 'BESD') & 0.040 & $<.001$ \\
\hline & & & & (compared to 'MLD') & -0.156 (if 'PD') & 0.093 & .047 \\
\hline & & & & Bullying pre-test & +0.300 & 0.028 & $<.001$ \\
\hline \multicolumn{4}{|c|}{$-2 *$ Log likelihood $=3943.555$} & $-2 *$ Log likelihood $=2047.083$ & & & \\
\hline \multicolumn{8}{|c|}{$X^{2}(66, n=1506)=1896.47, p<.001$} \\
\hline
\end{tabular}

Table 10

School and pupil level variables associated with statistically significant changes in bullying of pupils during the AfA pilot (secondary schools).

\begin{tabular}{|c|c|c|c|c|c|c|c|}
\hline \multicolumn{4}{|c|}{$\beta_{0 i j k}=0.554(0.555)$} & \multicolumn{4}{|l|}{$\beta_{0 i j k}=1.950(0.937)$} \\
\hline & Coefficient $\beta$ & SE & $p$ & & Co-efficient $\beta$ & SE & $p$ \\
\hline LA level & $\begin{array}{l}0.016 \\
3.9 \%\end{array}$ & 0.013 & .125 & LA level & $\begin{array}{l}0.001 \\
0 \%\end{array}$ & 0.000 & - \\
\hline \multirow[t]{2}{*}{ School level } & $\begin{array}{l}0.042 \\
10.2 \%\end{array}$ & 0.013 & $<.001$ & School level & $\begin{array}{l}0.000 \\
0 \%\end{array}$ & 0.000 & $<.001$ \\
\hline & & & & $\begin{array}{l}\text { \%FSM } \\
\text { Leadership (compared to 'no') } \\
\text { APP target review teachers } \\
\text { (compared to 'never') }\end{array}$ & $\begin{array}{l}+0.027 \\
-0.331 \\
-0.895 \text { (if 'often') }\end{array}$ & $\begin{array}{l}0.012 \\
0.120 \\
0.429\end{array}$ & $\begin{array}{l}.077 \\
.055 \\
.086\end{array}$ \\
\hline \multirow[t]{2}{*}{ Pupil level } & $\begin{array}{l}0.353 \\
85.9 \%\end{array}$ & 0.012 & $<.001$ & Pupil level & $\begin{array}{l}0.263 \\
100 \%\end{array}$ & 0.012 & $<.001$ \\
\hline & & & & $\begin{array}{l}\text { Year group (compared to 'Year 7') } \\
\text { FSM eligibility (compared to 'no') } \\
\text { \% Attendance (08/09) } \\
\text { Maths achievement (1-65) } \\
\text { SEND primary need } \\
\text { (compared to 'MLD') } \\
\text { Bullying pre-test }\end{array}$ & $\begin{array}{l}-0.073 \text { (if 'Year } 10^{\prime} \text { ) } \\
+0.102 \text { (if 'yes') } \\
+0.006 \\
-0.006 \\
+0.095 \text { (if 'BESD') } \\
+0.190 \text { (if 'PD') } \\
+0.287\end{array}$ & $\begin{array}{l}0.013 \\
0.040 \\
0.002 \\
0.003 \\
0.051 \\
0.106 \\
0.029\end{array}$ & $\begin{array}{l}<.001 \\
.005 \\
.001 \\
.023 \\
.032 \\
.037 \\
<.001\end{array}$ \\
\hline \multicolumn{4}{|c|}{$-2^{*} \log$ likelihood $=1657.156$} & $-2 * \log$ likelihood $=1359.963$ & & & \\
\hline
\end{tabular}

Inspection of Tables 5-10 reveals several trends. First, consistent with Hypothesis 2, both school- and individual-level differences accounted for statistically significant proportions of the variance in each model. School-level differences accounted for between $10.2 \%$ (secondary school bullying) and $20.2 \%$ (primary school bullying) of the variance in student outcomes, with individual differences between students accounting for between 79.8 (primary school bullying) and $89.8 \%$ (secondary school bullying). Second, consistent with Hypothesis 3, a number of school- and individual-level explanatory variables explained statistically significant proportions of this variance (albeit some to a marginal degree at $p<.10$ ). The overall improvements in model fit from the unconditional to conditional models are evidenced by statistically significant Chi-Square analyses of the changes in $2^{*} \log$ likelihood values in all six hierarchical models. Furthermore, by examining the changes in the model co-efficients at school and individual levels, the inclusion of our explanatory variables can be seen to account for between 37.5\% (primary school bullying) and 100\% (secondary school bullying, positive relationships, and behaviour) of the variance attributable to the school level, and between $25.5 \%$ (secondary school bullying) and $45.98 \%$ (primary school behaviour) of the variance attributable to the individual level (Muijs, 2011).

At the school level, contextual factors that influenced change in at least two of the models were the proportions of students from potentially vulnerable groups (e.g. FSM, EAL, and SAP/SSEN), aggregated outcome measures at pre-test, and 
school leadership for AfA. School-level implementation factors that influenced change in at least two of the models were structured conversation practice (e.g. dosage and/or fidelity to the SCP model), the frequency of teacher and/or parental involvement in reviewing APP targets, and the range/reach of methods of communication and intervention. These findings indicate that both the implementation environment and the quality of implementation practices were important mediators of intervention outcomes. Finally, at the individual level, students more likely to experience relatively better outcomes in at least two of the models were girls and more academically able students. Students more likely to experience relatively worse outcomes were older students, those eligible for FSM, and those identified as having BESD. These findings suggest AfA intervention gains varied considerably as a function of individual differences between students.

\section{Discussion}

The objectives of the current study were (i) to evaluate the impact of the AfA pilot on the behaviour, bullying and positive relationships of students with SEND, (ii) to determine the amount of variation in the above response variables that existed between and within schools, and (iii) to identify the characteristics at school and individual levels that explained significant variation in these outcomes. In relation to (i), our analyses revealed statistically significant effects in each of the three measured outcomes, in all cases in favour of the intervention group. Accompanying effect size analyses determined that these treatment effects were most likely practically meaningful. In relation to (ii), unconditional hierarchical linear models demonstrated that differences between schools were important, accounting for between $10.2 \%$ and $20.2 \%$ of the variance in student outcomes. However, individual differences always accounted for the majority (79.8-89.8\%) of the variation. Finally, in relation to (iii), conditional hierarchical models demonstrated the influence of a range of school-level contextual factors (e.g. proportion of students from potentially vulnerable backgrounds) and measures of AfA implementation quality (e.g. fidelity and dosage in relation to structured conversations with parents) on student outcomes. At the individual level, the same analyses suggested that differences in a range of characteristics predisposed some students to experience relatively better (e.g. girls) or worse (e.g. those eligible for FSM) outcomes than others.

The findings regarding the impact of AfA on students' wider outcomes align closely with our analyses of the pilot programme's impact on other variables, such as academic achievement in English and Maths (see Barlow et al., forthcoming; Humphrey \& Squires, 2011a, 2011b). Taken as a whole, our evaluation suggests that AfA can be considered an effective means of improving a range of outcomes for some of the most vulnerable and 'at risk' students in schools. Support is also provided for the integrated provision model proposed by Domitrovich, Bradshaw, and et al. (2010). AfA offers a useful case example of how a co-ordinated, synergistic blend of school-wide and targeted activities which focus upon a range of related outcomes can yield positive results. Of particular note are the theoretically plausible effects observed. AfA was clearly successful in promoting positive relationships and preventing/stabilising bullying and behaviour problems when compared to usual practice. Furthermore, although the treatment effect sizes noted would each be considered "small" using Cohen's (1992) criteria for the interpretation of $d$, reference to Durlak's (2009) guidance for the interpretation of $\mathrm{U}^{3}$ index scores suggests that with the possible exception of changes in positive relationships, they can nonetheless be considered practically meaningful, since "many educators would probably welcome a 10\% improvement" (p. 924).

However, basic consideration of mean treatment effects belies the variability that inevitably occurs when an intervention such as AfA is piloted. That schools' contextual features such as their overall levels of attainment and the composition of their student body will vary is a given. However, these aspects of the implementation environment have been somewhat neglected in prior research. Given this, the school-level contextual factors that contributed to variance in our outcome variables are particularly noteworthy, even if the picture is somewhat mixed. Taken as a whole, our analyses identified a 'vulnerability' effect, wherein the proportion of students belonging to one or more potentially vulnerable groups (e.g. those with SEND, eligible for FSM, and/or speaking EAL) at a given school interacted with the impact of AfA at the individual level. For three cases (\%FSM in the secondary bullying model, \%EAL in the primary bullying model, and \%SAP/SSEN in the primary positive relationships model), higher proportions of vulnerable students were associated with reduced treatment effects, perhaps indicating that need/demand outstripped the ability of such schools to respond. That is, there was reduced 'capacity for change' in Durlak and DuPre's (2008) terms. However, in two cases (\%SAP/SSEN in the secondary positive relationships model, \%SA in the primary bullying model), increased proportions of vulnerable students were actually associated with intensified treatment effects. The implication here is that although individual factors such as a strong perception of the need for an intervention may facilitate its implementation, it is the complex interaction of multiple factors rather than one dominant factor that influences the effectiveness of an intervention. This highlights the importance of examining implementation at multiple levels in order to fully understand how and why an intervention works (Lendrum \& Humphrey, 2012).

A further key element of the AfA implementation environment that had an effect on outcomes in two of our analyses was leadership. In primary schools where the AfA Lead was a member of the school's leadership team, there were greater reductions in behaviour problems. In secondary schools where this was the case, there were greater reductions in bullying. It has become something of a truism that the support provided by school leadership for any educational innovation or initiative is a crucial factor in determining whether it 'takes hold'. As Leithwood, Harris, and Hopkins (2008) state, 'Leadership acts as a catalyst without which other good things are unlikely to happen' (p. 28). School leadership support can influence implementation in many ways. For example, in setting school priorities, setting a clear vision, securing funding and other important resources, allocating time for training, and so on (Durlak \& DuPre, 2008). Indeed, in a large-scale school-based 
prevention survey by Gottfredson and Gottfredson (2002), leadership support was found to be one of the strongest correlates of a variety of implementation quality indicators. An important contribution of the current study is that is one of only a handful to connect leadership directly to variation in intervention outcomes.

The HLM analyses also spoke to the importance of different components of AfA implementation in facilitating positive outcomes at the individual level. Some of the recurrent themes that appeared in at least two of the analyses were dosage and/ or fidelity in the structured conversations with parents, the frequency of teacher and/or parental involvement reviewing APP targets, and the range/reach of methods of communication and intervention. These findings are important for two reasons. First, they reinforce the importance attributed to implementation quality in the school-based prevention literature (e.g. Durlak \& DuPre, 2008; Dusenbury et al., 2005). Second, they clearly demonstrate the inter-related nature of implementation activities and outcomes within and across domains. So, for example, implementation activities in the ATI and SCP strands were associated with improved outcomes in the PWO strand. This validates the argument outlined earlier, namely that interventions that target multiple factors and outcomes simultaneously in a coordinated manner are likely to have a synergistic effect (Domitrovich, Bradshaw, \& et al., 2010).

At the student level, our analyses suggested considerable variation in individual responsiveness to the AfA intervention. As above, there were several recurrent themes that appeared in at least two of the models. Groups of students more likely to experience relatively better outcomes included girls, and more academically able students (as judged by their attainment in English or Maths at pre-test). Those more likely to experience relatively worse outcomes were older students, those eligible for FSM, and those identified as having BESD. These findings resonate strongly with the handful of existing studies where sub-group analyses have been conducted (e.g. Ashdown \& Bernard, 2011; Holsen et al., 2009; Slee et al., 2009) in that they provide evidence to support a differential gains hypothesis for school-based intervention (Humphrey, 2013). In addition to adding to our understanding of the complexities of individual susceptibility to intervention effects and the implications of participant responsiveness as a factor affecting implementation (and therefore the achievement of expected outcomes), the findings also have practical implications, since they highlight groups of students who may require further, more intensive support that might be built into a future iteration of the integrated model of provision in AfA.

\subsection{Strengths and limitations of the study}

The current study was strengthened by a number of factors that increase our confidence that findings can be generalised to the wider population of students with SEND. The evaluation benefited from a very large sample of both schools and students, the opportunity to compare intervention effects with a usual practice control group, and the modelling of a range of school and individual differences that allowed for a more nuanced and rigorous analysis than is perhaps typical. More broadly, the study also provides a direct response to calls for comprehensive analysis of a range of implementation factors (e.g. Lendrum \& Humphrey, 2012) and modelling of differential effects among different subgroups of students (e.g. Durlak et al., 2011) in school-based intervention research. In doing so, it builds upon and adds to the extant literature. Perhaps most significantly, it is the first study to apply the theory, principles and practices of the prevention literature to the evaluation of a comprehensive intervention for students with SEND.

However, there were also some limitations that are worthy of note. First, the failure to randomise schools to intervention or control conditions means that potentially important school-level confounds may not be evenly distributed between the groups. Although our analyses suggested that schools in intervention and control groups were broadly comparable in terms of basic characteristics ( see Table 1), there may have been other, unmeasured differences between them that influenced our findings. Second, the large sample imbalance between intervention and control groups may have caused a loss of power and precision in our analyses (Elliott, McCaffrey, \& Lockwood, 2007). Given this, it is reassuring that with the marginal exception of changes in positive relationships, the $95 \%$ confidence intervals for the intervention and control groups in each outcome variable did not overlap. Finally, it was somewhat unusual that none of the implementation indicators for the PWO actually contributed to the PWO outcomes modelled in the study. Our feeling is that this is most likely a methodological/ measurement artefact. Thus, it may be that our PWO implementation items were not sensitive enough to detect differences between schools, which may have resulted in reduced variance in the ensuing data. This may have been accentuated by the use of self-report, as opposed to independent, ratings of implementation (Domitrovich, Gest, Jones, Gill, \& DeRousie, 2010).

\section{Conclusion}

The findings of the current study and our associated outputs (e.g. Barlow et al., forthcoming; Humphrey \& Squires, 2011a, 2011b) suggest that the Achievement for All programme is an effective means of improving outcomes for students with SEND. This represents a particularly significant advancement given the established vulnerabilities of this group of learners. Support is also provided for the theoretical propositions embedded within Domitrovich, Bradshaw, and et al.'s (2010) integrated model of provision; furthermore, this is the first study to apply the theory, principles and practices of the prevention literature to the evaluation of a comprehensive intervention for students with SEND. Our HLM analyses demonstrated that both school- and student-level differences played an important role in mediating impact at the individual level. As Vostanis, Humphrey, Fitzgerald, Wolpert, and Deighton (2012) have noted, school-based interventions do not occur in a vacuum, and these findings reiterate the importance of considering the range of contextual factors operating at different levels that may influence the success of efforts to remediate students' difficulties. However, demonstration of treatment 
effects - even those of likely practical as well as statistical significance - does not complete the picture. Two important 'next steps' are required. First, it is imperative to consider the cost-effectiveness and cost-benefits of AfA, in order to ensure that it is a sound investment for schools. Second, as the programme is brought to scale nationally (Department for Education, 2011), it is vital to transfer the learning from this evaluation. It is perhaps inevitable that aspects of AfA will be modified, adapted and/or diluted. Indeed, this is a common occurrence when interventions are disseminated (Elias, Zins, Graczyk, \& Weissberg, 2003). Given this, it may be helpful to consider the implementation 'must dos' that the analyses reported in this and our other outputs suggest are necessary conditions for success.

\section{References}

Ashdown, D. M., \& Bernard, M. E. (2011). Can explicit instruction in social and emotional learning skills benefit the social-emotional development, well-being, and academic achievement of young children? Early Childhood Education Journal, 39, 397-405.

Australian Institute of Health and Welfare. (2004). Children with disabilities in Australia. Canberra: AIHW.

Barlow, A., \& Humphrey, N. (2012). A natural variation study of engagement and confidence among parents of learners with special educational needs and disabilities (SEND). European Journal of Special Needs Education, iFirst, 27, 447-467.

Barlow, A., Humphrey, N., Lendrum, A., Wigelsworth, M. \& Squires, G. (in press). Achievement for All: Narrowing the attainment gap for students with special educational needs and disabilities. To be submitted to Exceptional Children.

Blakely, C. H., Mayer, J. P., Gottschalk, R. G., Schmitt, N., Davidson, W. S., Roitman, D. B., et al. (1987). The fidelity-adaptation debate: Implications for the implementation of public sector social programs. American Journal of Community Psychology, 15, 253-268.

Castro, F. G., Barrera, M., \& Martinez, C. R. (2004). The cultural adaptation of prevention interventions: Resolving tensions between fidelity and fit. Prevention Science, 5, 41-45.

Cohen, J. (1992). A power primer. Psychological Bulletin, 112, 155-159.

Dane, A. V., \& Schneider, B. H. (1998). Program integrity in primary and early secondary prevention: Are implementation effects out of control? Clinical Psychology Review, 18, 23-45.

Davis, P., Florian, L., Ainscow, M., Dyson, A., Farrell, P., Hick, P., et al. (2004). Teaching strategies and approaches for pupils with special educational needs: A scoping study. Nottingham: DfES Publications.

Department for Children Schools and Families. (2009). Getting to grips with assessing pupils' progress. Nottingham: DCSF Publications.

Department for Education. (2010a). Children with special educational needs 2010: An analysis. London: DFE Publications.

Department for Education. (2010b). Schools, pupils and their characteristics. London: DFE Publications.

Department for Education. (2010c). Pupil absence in schools in England, autumn term 2009 and spring term 2010. London: DFE Publications.

Department for Education. (2010d). National curriculum assessments at Key Stage 2 in England, 2009/10 (revised). London: DFE Publications.

Department for Education. (2010e). GCSE and equivalent results in England, 2009/10 (revised). London: DFE Publications.

Department for Education. (2011). Support and aspiration: A new approach to special educational needs and disability. Nottingham: DFE Publications.

Department for Education and Skills. (2001). Special educational needs: Code of practice. Nottingham: DFES Publications.

Domitrovich, C. E., Bradshaw, C. P., Greenberg, M. T., Embry, D., Poduska, J. M., \& Ialongo, N. S. (2010). Integrated models of school-based prevention: Logic and theory. Psychology in the Schools, 47, 71-88.

Domitrovich, C. E., Gest, S. D., Jones, D., Gill, S., \& DeRousie, R. M. S. (2010). Implementation quality: Lessons learned in the context of the Head Start REDI trial. Early Childhood Research Quarterly, 25, 284-298.

Durlak, J. (2010). The importance of doing well in whatever you do: A commentary on the special edition, implementation research in early childhood education. Early Childhood Research Quarterly, 25, 348-357.

Durlak, J. A., \& DuPre, E. P. (2008). Implementation matters: A review of research on the influence of implementation on program outcomes and the factors affecting implementation. American Journal of Community Psychology, 41, 327-350.

Durlak, J. A. (2009). How to select, calculate, and interpret effect sizes. Journal of Pediatric Psychology, 34, 917-928.

Durlak, J. A., Weissberg, R. P., Dymnicki, A. B., Taylor, R. D., \& Schellinger, K. B. (2011). The impact of enhancing students' social and emotional learning: A metaanalysis of school-based universal interventions. Child Development, 82, 405-432.

Dusenbury, L., Brannigan, R., Hansen, W. B., Walsh, J., \& Falco, M. (2005). Quality of implementation: Developing measures crucial to understanding the diffusion of preventive interventions. Health Education Research, 20, 308-313.

Elias, M. J., Zins, J. E., Graczyk, P., \& Weissberg, R. P. (2003). Implementation, sustainability, and scaling up of social-emotional and academic innovations in public schools. School Psychology Review, 32, 303-319.

Elliott, D., \& Mihalic, S. (2004). Issues in disseminating and replicating effective prevention programs. Prevention Science, 5, 47-53.

Elliott, M. N., McCaffrey, D. F., \& Lockwood, J. R. (2007). How important is exact balance in treatment and control sample sizes to evaluations? Journal of Substance Abuse Treatment, 33, 107-110.

Farrell, P. (2012). Inclusive education for children with special educational needs: Current uncertainties and future directions. In D. Armstrong \& G. Squires (Eds.), Contemporary issues in special educational needs: Considering the whole child (pp. 35-47). Maidenhead: McGraw-Hill.

Florian, L. (2007). Reimagining special education. In L. Florian (Ed.), The sage handbook of special education (pp. 7-20). London: Sage Publications.

Frederickson, N. L., \& Furnham, A. F. (2004). Peer-assessed behavioural characteristics and sociometric rejection: Differences between pupils who have moderate learning difficulties and their mainstream peers. The British journal of Educational Psychology, 74, 391-410.

Frostad, P., \& Pijl, S. J. (2007). Does being friendly help in making friends? The relation between the social position and social skills of pupils with special needs in mainstream education. European Journal of Special Needs Education, 22, 15-30.

Gottfredson, D., \& Gottfredson, G. (2002). Quality of school-based prevention programs: Results from a national survey. Journal of Research in Crime and Delinquency, 39, 3-35.

Green, H., McGinnity, A., Meltzer, H., Ford, T., \& Goodman, R. (2005). Mental health of children and young people in Great Britain. Cardiff: ONS.

Greenberg, M., Domitrovich, C., Graczyk, P., \& Zins, J. (2005). The study of implementation in school-based preventive interventions: Theory, research, and practise. Rockville: CMHS.

Holsen, I., Iversen, A. C., \& Smith, B. H. (2009). Universal social competence promotion programme in school: Does it work for children with low socio-economic background? Advances in School Mental Health Promotion, 2, 51-60.

Humphrey, N., Lendrum, A., \& Wigelsworth, M. (2010). Secondary social and emotional aspects of learning (SEAL): National evaluation. Nottingham: DFE Publications.

Humphrey, N., \& Squires, G. (2011a). Achievement for All national evaluation: Second interim report. Nottingham: DFE Publications.

Humphrey, N., Wigelsworth, M., Barlow, A., \& Squires, G. (2012). The role of school and individual differences in the academic attainment of learners with special educational needs and disabilities: A multi-level analysis. International Journal of Inclusive Education, iFirst, 1-23.

Humphrey, N. Social and emotional learning: A critical appraisal. London: Sage Publications, 2013.

Humphrey, N., \& Squires, G. (2010). Achievement for All national evaluation: Interim report. Nottingham: DFE Publications.

Humphrey, N., \& Squires, G. (2011b). Achievement for All national evaluation: Final report. Nottingham: DFE Publications.

Humphrey, N., \& Symes, W. (2010). Perceptions of social support and experience of bullying among pupils with autistic spectrum disorders in mainstream secondary schools. European Journal of Special Needs Education, 25, 77-91.

Institute of Education Sciences. (2011). Digest of education statistics 2010. Washington, DC: IES.

Joyce, B., \& Showers, B. (2002). Student achievement through staff development (3rd ed.). Alexandria, VA: Association for Supervision and Curriculum Development. 
Kam, C.-M., Greenberg, M. T., \& Walls, C. T. (2003). Examining the role of implementation quality in school-based prevention using the PATHS curriculum. Prevention Science, 4, 55-63.

Kaukiainen, A., Salmivalli, C., Lagerspetz, K., Tamminen, M., Vauras, M., Mäki, H., et al. (2002). Learning difficulties, social intelligence, and self-concept: Connections to bully-victim problems. Scandinavian Journal of Psychology, 43, 269-278.

Kavale, K. A. (2007). Quantitative research synthesis: Meta-analysis of research on meeting special educational needs. In L. Florian (Ed.), The sage handbook of special education (pp. 207-221). London: Sage.

Leithwood, K., Harris, A., \& Hopkins, D. (2008). Seven strong claims about successful school leadership. School Leadership E Management, 28, 27-42.

Lendrum, A. (2010). Implementing social and emotional aspects of learning (SEAL) in secondary schools in England: Issues and implications. Unpublished PhD thesis. University of Manchester.

Lendrum, A., \& Humphrey, N. (2012). The importance of studying the implementation of school-based interventions. Oxford Review of Education, iFirst, 38, 635-652.

Lendrum, A., Barlow, A. \& Humphrey, N. (in press). Developing positive school-home relationships through structured conversations with parents of learners with special educational needs and disabilities. To be submitted to British Journal of Special Education.

Lewis, A., \& Norwich, B. (2005). Special teaching for special children? Maidenhead: Open University Press.

Mand, J. (2007). Social position of special needs pupils in the classroom: A comparison between German special schools for pupils with learning difficulties and integrated primary school classes. European Journal of Special Needs Education, 22, 7-14.

Masten, A. S., \& Obradovic, J. (2006). Competence and resilience in development. Annals of the New York Academy of Sciences, $1094,13-27$.

McKinney, J., \& Feagans, L. (1984). Academic and behavioral characteristics of learning disabled children and average achievers: Longitudinal studies. Learning Disability Quarterly, 7, 251-265.

Monchy, M. D., Pijl, S. J., \& Zandberg, T. (2004). Discrepancies in judging social inclusion and bullying of pupils with behaviour problems. European Journal of Special Needs Education, 19, 317-330.

Muijs, D. (2011). Doing quantitative research in education with SPSS (2nd ed.). London: Sage.

Norwich, B. (2005). Inclusion: Is it a matter of evidence about what works or about values and rights? Education 3-13, 33, 37-41.

Office for Standards in Education. (2010). The special educational needs and disability review: A statement is not enough. London: OFSTED.

Pijl, S. J., Frostad, P., \& Flem, A. (2008). The social position of pupils with special needs in regular schools. Scandinavian Journal of Educational Research, 52, 387-405.

Raudenbush, S. (2008). Advancing educational policy by advancing research on instruction. American Educational Research Journal, 45, $206-230$.

Raudenbush, S. W., \& Bryk, A. S. (2002). Hierarchical linear models. Thousands Oaks, CA: Sage Publications.

Ringwalt, C., \& Ennett, S. (2003). Factors associated with fidelity to substance use prevention curriculum guides in the nation's middle schools. Health Education, $30,375-391$

Robinson, P., \& Oppenheim, C. (1998). Social exclusion indicators. London: IPPR.

Robson, C. (2005). Students with disabilities, learning difficulties and disadvantages: Statistics and indicators. Paris, France: OECD.

Rogers, E. M. (2003). Diffusion of innovations. New York, NY: Free Press.

Sabornie, E. (1994). Social-affective characteristics in early adolescents identified as learning disabled and nondisabled. Learning Disability Quarterly, 17(4), $268-279$.

Slee, P., Lawson, M., Russell, A., Askell-Williams, H., Dix, K., Owens, L., et al. (2009). Kidsmatter primary evaluation final report. Flinders, Australia: University of Flinders.

Squires, G. (2012). Historical and socio-political agendas around defining and including children with special educational needs. In Armstrong, D., \& Squires, G. (Eds.), Contemporary issues in special educational needs: Considering the whole child (27, pp. 469-481). Maidenhead: McGraw-Hill.

Squires, G., Humphrey, N., Barlow, A., \& Wigelsworth, M. (2012). The identification of special educational needs and month of birth: Differential effects of category of need and level of assessment. European Journal of Special Needs Education27 iFirst.

Symes, W., \& Humphrey, N. (2012). Including pupils with autistic spectrum disorders in the classroom: The role of teaching assistants. European Journal of Special Needs Education, 27, 517-532, iFirst.

Terwee, C. B., Bot, S. D. M., de Boer, M. R., van der Windt, D. A. W. M., Knol, D. L., Dekker, J., et al. (2007). Quality criteria were proposed for measurement properties of health status questionnaires. Journal of Clinical Epidemiology, 60, 34-42.

Thomas, G., \& Loxley, A. (2007). Deconstructing special education and constructing inclusion. Buckingham: Open University Press.

Thompson, D., Whitney, I., \& Smith, P. (1994). Bullying of children with special needs in mainstream schools. Support for Learning, 9, 103-106.

United Nations Educational, Scientific and Cultural Organisation. (1994). The Salamanca statement and framework for action on special needs education. Salamanca, Spain: UNESCO.

ValÅs, H. (1999). Students with learning disabilities and low-achieving students: Peer acceptance, loneliness, self-esteem, and depression. Social Psychology of Education, 3, 173-192.

Van Cleave, J., \& Davis, M. M. (2006). Bullying and peer victimization among children with special health care needs. Pediatrics, $118,1212-1219$.

Vostanis, P., Humphrey, N., Fitzgerald, N., Wolpert, M., \& Deighton, J. (2012). How do schools promote emotional wellbeing among their pupils? Findings from a national scoping survey of mental health provision in English schools. Child and Adolescent Mental Health, Early View, 1-7, iFirst.

Zhang, D., Katsiyannis, a., \& Kortering, L. J. (2007). Performance on exit exams by students with disabilities: A four-year analysis. Career Development for Exceptional Individuals, 30, 48-57. 